\title{
Mémoire des lieux, lieux de mémoire
}

\section{Christophe Didier}

\section{(2) OpenEdition}

\section{Journals}

Édition électronique

URL : https://journals.openedition.org/rbnu/2803

DOI : $10.4000 /$ rbnu. 2803

ISSN : 2679-6104

\section{Éditeur}

Bibliothèque nationale et universitaire de Strasbourg

\section{Édition imprimée}

Date de publication : 1 mai 2012

Pagination : 7

ISSN : 2109-2761

\section{Référence électronique}

Christophe Didier, « Mémoire des lieux, lieux de mémoire », La Revue de la BNU [En ligne], 5 | 2012, mis en ligne le 01 mai 2012, consulté le 25 août 2021. URL : http://journals.openedition.org/rbnu/2803 ; DOI : https://doi.org/10.4000/rbnu.2803

Ce document a été généré automatiquement le 25 août 2021.

\section{(c) (i) (2)(2)}

La Revue de la BNU est mise à disposition selon les termes de la Licence Creative Commons Attribution - Pas d'Utilisation Commerciale - Partage dans les Mêmes Conditions 4.0 International. 


\title{
Mémoire des lieux, lieux de mémoire
}

\author{
Christophe Didier
}

«Le vieux Paris n'est plus (la forme d'une ville / change plus vite, hélas! que le cœur d'un mortel) ». Ces vers bien connus de Baudelaire, combien ont pu les méditer face aux destins brutaux qui ont touché tant de lieux et semblent quelquefois consubstantiels à l'aventure des peuples et des civilisations. L'évocation élégiaque est si souvent le corollaire inévitable de la mémoire des choses... Et pourtant, au sein même de ces perturbantes métamorphoses, cette mémoire résiste et resurgit parfois de façon inattendue. Voici par exemple la ville de Königsberg: l'ancienne capitale de la PrusseOrientale était devenue mythique tant on la pensait rayée de la carte avec la disparition, historique aussi bien que géographique, de l'État qui l'avait vue naître. Or voici qu'on retrouve des traces de ses bibliothèques que l'on croyait perdues; voici que la Russie elle-même renoue, à petits pas, avec le passé germanique de son enclave occidentale; voici l'Université fédérale baltique Emmanuel Kant qui succède à l'Institut pédagogique fondé avec la ville nouvelle de Kaliningrad.

2 Le mythe parfois demeure : on sait bien qu'on ne retrouvera sans doute jamais de traces de la bibliothèque d'Alexandrie. On sait aussi que celles de l'Atlantide sont surtout celles des poètes qui en entretiennent sans trêve la légende. Jouer avec la mémoire, faire parler les lieux de façon insolite, c'est aussi, parfois, le but de l'action artistique et de l'acte créateur, comme le rappellent dans ce numéro Marc Pessin et Alberto Manguel. Pour autant, les «lieux de mémoire » sont partout, preuve que la mémoire des lieux est bien plus solide que ne le sont les lieux eux-mêmes. L'historien sait pouvoir la retrouver dans les dépôts d'archives, le lecteur curieux se doute que maint ouvrage lui en offrira les clés, parfois de façon inattendue et paradoxale, comme ce pan de l'histoire intellectuelle de Königsberg qu'abrite la Bibliothèque nationale et universitaire de Strasbourg. 


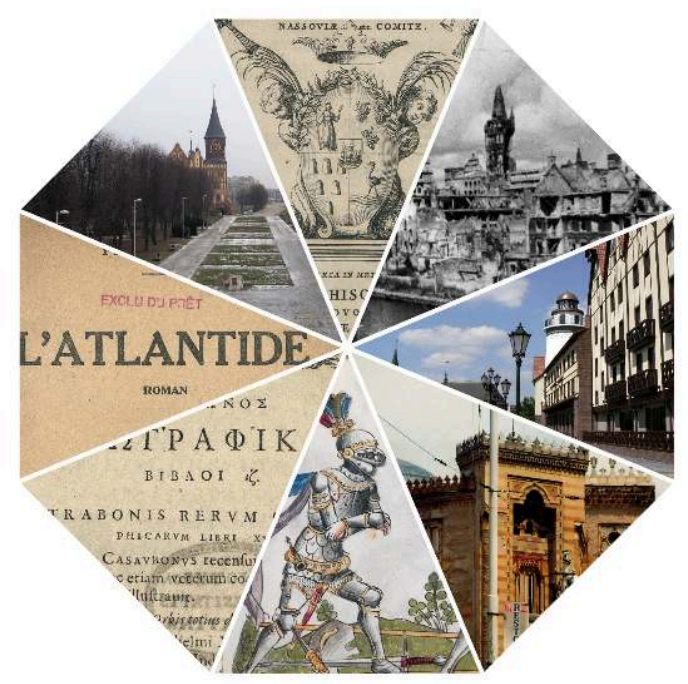

Cliché JPR-Bnu CC-BY-NC-SA

3 Elle est fragile cependant, et sa préservation est bien souvent à l'œuvre dans l'action des intellectuels, que l'on voit par exemple combattre l'oubli qui pourrait menacer le souvenir de la Sarajevo d'avant les partitions meurtrières qui ont secoué l'exYougoslavie. C'est ce que nous enseignent aussi les actions entreprises pour valoriser le patrimoine, devenu commun, des Polonais et des Allemands, dont une partie de l'héritage culturel, translaté lors des bouleversements issus de la Seconde Guerre mondiale, se trouve aujourd'hui géographiquement dispersé.

Combattre la dispersion, œuvrer à la refondation d'un socle culturel commun, lorsque celui-ci a été malmené par les vicissitudes de l'Histoire, c'est aussi la vocation des « lieux de mémoire " que constituent les établissements culturels. C'est en particulier une des raisons d'être, et non la moins noble, des bibliothèques dont les réservoirs de connaissances que constituent les fonds doivent sans cesse être interrogés, et dont nous avons à nous souvenir des leçons.

\section{AUTEUR}

\section{CHRISTOPHE DIDIER}

Rédacteur en chef 